Chikwendu Ibebunjo DVM PhD, *

Coimbatore B. Srikant PhD, $\dagger$

François Donati PhD MD FRCPC*ł

\title{
Duration of succinyl- choline and vecuro- nium blockade but not potency correlates with the ratio of endplate size to fibre size in seven muscles in the goat
}

Purpose: Muscles differ in their response to neuromuscular relaxants. This study investigated whether (1) the relative responses of muscles is inverted between succiny/choline (SUX) and vecuronium (VEC), and (2) differences in dose-response or duration of action are related to the morphology of fibres, endplates and acetylcholine receptors (AChR) in muscles.

Methods: In goats during thiopentone anaesthesia, the evoked EMG response to indirect train-of-four stimulation was monitored and the cumulative dose-response curves and duration

\section{Key words}

NEUROMUSCULAR RELAXANTS: succinylcholine, vecuronium;

MUSCLE, SKEL_ETAL: cricoarytenoideus dorsalis, thyroarytenoideus, diaphragm, soleus, gastrocnemius, transversus abdominis, rectus abdominis: morphology; NEUROMUSCULAR JUNCTION: acetylcholine receptor.

From the Departments of Anaesthesia* and Medicine $\dagger$, Royal Victoria Hospital and McGill University, Montréal, Québec, Canada H3A 1 Al.

$\ddagger$ Present address: Department of Anesthesia, Hotel-Dieu

Hospital and University of Montréal, Montréal, Canada. Address correspondence to: Dr. C. Ibebunjo, Shriners Burns Institute Research Center, BIdg., 1400, One Kendall Square, Cambridge, MA 02139 , U.S.A.

C.I. held a Royal Victoria Hospital Research Institute Fellowship and an FRSQ Fellowship during this study. This work was presented in part at the 5 I st Canadian Anaesthetists' Sociely Meeting, Junc 1994, Edmonton, Alberta, and at the XIIth International Congress of Pharmacology, July 1994. Montreal, Quebec.

Accepted for publication 19th January, 1996. of action of SUX and VEC in the diaphragin, cricoarytenoideus dorsalis, thyroarytenoideus, transversus abdominis, rectus abdominis, soleus and gastrocnemius muscles were deternined and related to their fibre composition, fibre size, endplate size, endplate to fibre size ratio, AChR number or $A C h R$ density by regression analysis.

Results: There were no differences in the $E D_{50}$ s of SUX [range, $119 \pm 1$ (1) (SE) to $159 \pm 20 \mu \mathrm{g} \cdot \mathrm{kg}^{-1}$ ] or VEC [range, $2.8 \pm 0.2$ to $3.7 \pm 0.8 \mu \mathrm{g} \cdot \mathrm{kg}^{-1} \mathrm{~J}$ among muscles. With either drug, duration to $25 \%$ or $50 \% T_{1}$ recovery was shortest at the laryngeal muscles and longest at abdominal muscles $(P=$ $0.0001)$, and correlated directly with fibre size ( $r \geq 0.40 ; P<$ 0.004 ) and inversely with the endplate to fibre size ratio ( $r \geq$ $0.40 ; P<0.008$ ).

Conclusion: The results show that (I) the relative responses of muscles do not differ between depolarizing and non-depolarizing relaxants; (2) the duration of blockade is shorter in muscles composed of small fibres with large endplates relative to fibre size; and (3) there is no relation between fibre type composition and sensitivity to muscle relaxants.

Objectif: Les muscles ne répondent pas tous de la même façon aux relaxants musculaires. Ce travail visait à étudier I) si la réponse relative des muscles était inversée entre la succinylcholine (SUX) et le vécuronium (VEC), et 2) les différences de la relation dose à effet et la durée d'action étaient en rapport avec la morphologie des fibres, des plaques motrices et des récepteurs acétylcholinergiques (AChR) des muscles.

Méthodes: Chez des chèvres anesthésiées au thiopentone, la réponse EMG évoquée à la stimulation du train-de-quatre a été monitorisée. Des courbes dose à effet, et la durée d'action de SUX et VEC au niveau du diaphragme, des muscles cricoaryténö̈diens, postérieurs, thyroaryténoïdien, transverses de l'abdomen, soléaires et gastrocnémiens ont été déterminées 
par analyse de régression en relation avec la composition des fibres, leur dimension, la rapport entre la dimension des plaque motrices et des fibres, le nombre et la densité d'AChR. Résultats: L'ED $D_{50}$ de SUX [étendue, $119 \pm 11$ (ET) à $159 \pm 20$ $\mu \mathrm{g} \cdot \mathrm{kg}^{-1}$ ] et de VEC [étendue, 2,8 $\pm 0,2$ à 3,7 $\pm 0,8 \mu \mathrm{g} \cdot \mathrm{kg}^{-1}$ ] était la même pour tous les muscles. Avec chacun des deux relaxants, la durée de récupération de $T$, de $25 \%$ ou $50 \%$ était plus courte au niveau des muscles laryngés et plus longue au niveau des muscles abdominaux $(P=0,0001)$ et était en corrélation directe avec la dimension des fibres $(r \geq 0,40, P<$ 0,008 ).

Conclusion: Ces résultats montrent que 1) la réponse relative des muscles est identique entre les relaxants dépolarisants et non dépolarisants; 2) la durée d'action est plus courte pour les muscles composés de petites fibres avec des grandes plaques motrices relativement à la dimension des fibres; et 3) il n'existe pas de rapport entre le type de fibre et la sensibilité aux relaxants musculaires.

Mammalian striated muscles differ in their response to muscle relaxant drugs with respect to onset time, intensity and duration of paralysis. ${ }^{1-9}$ These differences have important clinical implications but human data are fragmentary in this regard because most muscles are inaccessible to monitoring. Therefore, it is important to identify what factors determine sensitivity to muscle relaxant drugs.

Early experimental studies in cats found that slow-twitch muscles were less sensitive to decamethonium and more sensitive to d-tubocurarine than fast-twitch muscles. ${ }^{1.2}$ This suggested that (1) the relative sensitivities of muscles may be inverted between depolarizing and non-depolarizing relaxants, and (2) the response of muscles to relaxant drugs might be related to their fibre type composition. However, these relationships have not been confirmed in all cases. ${ }^{4.6 .10-15}$ In most of these studies, muscle fibre composition was not established in the animals studied but was obtained from other animals. Other explanations that have been proposed for the unequal responses of muscles to relaxant drugs include differences in fibre size, ${ }^{16}$ muscle temperature, ${ }^{17}$ acetylcholinesterase activity, and the number or affinity of acetylcholine receptors ${ }^{18}$ but only few studies have investigated these possibilities. A recent study found a direct association between muscle fibre size and duration of either succinylcholine or vecuronium blockade in four muscles in the goat, but the reason for this association was not elucidated neither were the dose-response curves at the four muscles determined. ${ }^{15}$ Since relaxant drugs produce their effects by interacting with acetylcholine receptors at the motor endplates, an association between fibre size and duration of blockade would imply that fibre size is related to some properties of the neuromuscular junction and/or acetylcholine receptors.

In this study the effective doses $\left(E D_{50} \mathrm{~s}\right)$ and duration of action of succinylcholine and vecuronium at the cricoarytenoideus dorsalis, thyroarytenoideus, diaphragm, rectus abdominis, transversus abdominis, gastrocnemius and soleus muscles of the goat were compared to determine (1) whether the relative sensitivities of these muscles (as judged by two different indices, namely, the $\mathrm{ED}_{50}$ and duration of blockade) depend on the type of relaxant drug; and (2) the influence on muscle sensitivity of fibre composition, fibre size, endplate size, the endplate to fibre size ratio, and the number or density of acetylcholine receptors determined on biopsies of these muscles taken from the same goats used for the neuromuscular studies.

\section{Methods}

\section{Animals}

Fourteen adult female goats of the Saanen breed were used for this study after approval by the Animal Care Sub-Committee of McGill University. Seven goats [age $24.7 \pm 13.5$ (SE) months; body weight, $30.3 \pm 11.5 \mathrm{~kg}$.] were used to study succinylcholine chloride (Queli$\operatorname{cin}^{\mathrm{TM}}$, Abbott Laboratories Ltd, Montreal, Canada) and the other seven (age $25.6 \pm 2.3$ months; body weight, $29.9 \pm 2.4 \mathrm{~kg}$ ) to study vecuronium bromide (Norcuron $^{\circledR}$, Organon Canada, West Hill, Ontario, Canada).

\section{Anaesthesia}

Following 12-18 hr fasting but not water deprivation, anaesthesia was induced with $10 \mathrm{mg} \cdot \mathrm{kg}^{-1}$ thiopentone and the trachea was intubated with an $8-9 \mathrm{~mm}$ (internal diameter) cuffed tube. Anaesthesia was maintained with continuous intravenous infusion of thiopentone and mechanical ventilation instituted with oxygen at $\sim$ eight brcaths per minute using $\sim 5 \mathrm{~L} \cdot \mathrm{min}^{-1}$ minute volume to maintain end-tidal $\mathrm{CO}_{2}\left(\mathrm{PETCO}_{2}\right)$ at $33-37 \mathrm{~mm} \mathrm{Hg}$ (Ohmeda $5200 \mathrm{CO}_{2}$ Monitor, BOC Health Care, USA). The carotid artery was cannulated for monitoring arterial blood pressure and the external jugular vein for drug administration. Rectal temperature was maintained at $37.0 \pm 1{ }^{\circ} \mathrm{C}$ with heating lamps, and together with $\mathrm{PETCO}_{2}$, the heart rate and arterial blood pressure (Models 78203A and 78205B, Hewlett-Packard, USA) was monitored continuously and maintained within physiological range.

\section{Surgical preparation}

During anaesthesia evoked EMG recordings were made from the seven muscles during train-of-four stimulation 
of their corresponding nerve supplies. With the animal in lateral recumbency and the upper hindlimb stabilized in a horizontal position, the sciatic nerve was surgically exposed in the thigh and attached to a stimulating electrode. The gastrocnemius and soleus muscles were exposed and bipolar fish-hook electrodes with an interelectrode distance of $\sim 1 \mathrm{~cm}$ inserted into them. A thermistor probe Model YSI ${ }^{\circledR} 6394$ (Temp Medical Products Inc., Florida, USA) was inserted subcutaneously over the gastrocnemius muscle for estimating limb muscle temperature which was maintained within $1^{\circ} \mathrm{C}$ of rectal temperature using heating lamps. The larynx and trachea were exposed through a ventro-lateral cervical incision and the recurrent laryngeal nerve isolated midway between the larynx and thoracic inlet and atlached to a stimulating electrode. Bipolar fine wire electrodes (225 $\mu \mathrm{m}$ external diameter; Cooner Wire Company, Chatsworth, California, USA) were inserted with the aid of hypodermic needles into the cricoarytenoideus dorsalis and thyroarytenoideus muscles as described previously. ${ }^{19}$ An interelectrode distance of $\sim 5$ $\mathrm{mm}$ parallel to the fibres was used for these laryngeal muscles. An eighth or ninth intercostal space thoracotomy was performed, a stimulating electrode attached to the phrenic nerve within the thoracic cavity before it entered the ipsi-lateral hemi-diaphragm, and bipolar fish-hook electrodes inserted into the costal diaphragm. The 10th intercostal nerve was isolated in the dorsal third of the rib cage and attached to a stimulating electrode. The rectus and transversus abdominis muscles were exposed between the ribcage and umbilicus and bipolar fish-hook electrodes inserted into them. The stimulating and recording electrodes used in this study were designed such that their active surface made contact only with the nerve or muscle under study. All surgical incisions were covered with wet swabs to maintain the vitality of the tissues.

\section{Pharmacodynamic studies}

The EMG electrodes from all seven muscles were connected via an eight-channel-input, four-channel-output switch-box to four Grass polygraph DC Amplifiers Model 7DA via wide band AC Preamplifiers and Integrators Model 7P3 (Grass Instrument Co., Quincy, Mass, USA). The "switch-box" was used to change from one EMG electrode to another thus allowing two muscles to be connected to the same amplifier. The sciatic, recurrent laryngeal, phrenic and intercostal nerves were stimulated simultaneously at $2 \mathrm{~Hz}$ for two seconds (train-of-four stimulation) every 12 seconds with supramaximal stimuli of $0.2 \mathrm{msec}$ duration using Grass Square pulse stimulators Model S88 and SIU5 stimulus isolation units. The evoked EMG response was wide-band filtered $(0.15 \mathrm{~Hz}-3 \mathrm{KHz})$, full-wave rectified and integrated, and the output was recorded on a four-channel polygraph Model 7S1225 (Grass Instruments Co.).

After recording stable control evoked EMG from all muscles, cumulative doses of the drug were given intravenously as rapid boluses while monitoring the evoked response. For succinylcholine, an initial dose of 100 $\mu \mathrm{g} \cdot \mathrm{kg}^{-1}$ was given followed by $50 \mu \mathrm{g} \cdot \mathrm{kg}^{-1}$ increments. For vecuronium, initial and incremental doses of 2 $\mu \mathrm{g} \cdot \mathrm{kg}^{-1}$ were used. Incremental doses of the drug were given when three equal consecutive first twitch $\left(\mathrm{T}_{1}\right)$ responses were observed in. all muscles or when evidence of recovery (increasing $T_{1}$ response) appeared in any muscle. This process was repeated until at least $90 \% T_{1}$ depression was reached in all muscles. The interval between doses averaged $1.5 \mathrm{~min}$ for succinylcholine and $4.5 \mathrm{~min}$ for vecuronium. Two to five data points were obtained per muscle. At the end of the dose-response studies, the evoked response was allowed to recover spontaneously to a stable maximal level in all muscles, and the experiment was terminated.

The $\mathrm{ED}_{50}\left(\mu \mathrm{g} \cdot \mathrm{kg}^{-1}\right)$ for each drug in each muscle was calculated by linear regression of the logit transformation of maximum $T_{1}$ depression after each dose and the logarithm of the cumulative dose given. Since differences in onset times were less marked after several dose increments, the maximum $T_{1}$ blockade after a cumulative dose of succinylcholine, $200 \mu \mathrm{g} \cdot \mathrm{kg}^{-1}$, or vecuronium, $4 \mu \mathrm{g} \cdot \mathrm{kg}^{-1}$, was measured. The duration (minutes) for spontaneous recovery of evoked EMG from maximum blockade to $25 \%$ and $50 \%$ of maximal evoked $\mathrm{T}_{\mathrm{I}}$ recovery were determined for each muscle, drug and goat.

\section{Histological and autoradiographic studies}

At the end of the pharmacodynamic neuromuscular studies biopsies were taken from the seven muscles as well as the masseter muscle, and the fibre type composition, fibre cross-sectional area, endplate surface area, and junctional acetylcholine receptor number and receptor density determined as described in detail elsewhere. $^{20}$

\section{Statistical analysis}

The mean $\left( \pm \mathrm{SE}\right.$ ) of the $\mathrm{ED}_{50} \mathrm{~s}$, maximum $\mathrm{T}_{1}$ depression after a cumulative dose of succinylcholine, $200 \mu \mathrm{g} \cdot \mathrm{kg}^{-1}$, or vecuronium, $4 \mu \mathrm{g} \cdot \mathrm{kg}^{-1}$, and duration to $25 \%$ and $50 \% \mathrm{~T}_{1}$ recovery were compared among muscles by one-way ANOVA and the Scheffe test. For comparison of the duration of paralysis, duration to $25 \%$ and $50 \% \mathrm{~T}_{1}$ at each muscle were expressed as a fraction of that at the gastrocnemius muscle in the same goat and this normal- 
ized value compared. This was necessary because the total quantity of the drug given and the interval over which it was given varied from one goat to another. However, although the normalized duration data were used for statistical analysis, the absolute values are presented in the results (Tables I and II).

To verify whether the relative responses of the seven muscles depended on the type of relaxant drug, the rank order of the $E D_{50} \mathrm{~s}$, duration to $25 \% \mathrm{~T}_{1}$ or duration to $50 \% \mathrm{~T}_{\text {, recovery after succinylcholine }}$ were related to that after vecuronium by Spearman's rank correlation. The association between fibre composition, fibre cross-sectional area, endplate surface area, the ratio of endplate area to fibre area (ESA:CSA ratio), acetylcholine receptor number or receptor density versus the $E D_{50}$, maximum $T_{1}$ blockade, duration to $25 \%$ or $50 \% \mathrm{~T}$, recovery after either succinylcholine or vecuronium were investigated by Spearman's rank correlation or linear regression analysis as appropriate. The above analyses were performed using StatView $512+^{\mathrm{TM}}$ (version 1.2, BrainPower, Inc) on a Macintosh computer. Multivariate analysis of variance performed using STATISTICA ${ }^{\mathrm{TM}}$ for Windows on a PC showed that there were no interactions between the various fibre morphologic variables in predicting muscle response to relaxant drugs. $P \leq 0.05$ was considered statistically significant. Results are presented as mean \pm SEM

\section{Results}

\section{Comparative muscle response}

\section{GENERAL. OBSERVATIONS}

Prior to administration of the relaxant drugs, the train-of-four ratio was $>0.94$ in all muscles in all goats. Following administration of the relaxant drug, the evoked response did not always recover to control levels. The maximum recovery atlained (range: $70-105 \%$ of control $T_{1}$; train-of-four ratio, 0.8-1.0) did not differ among muscles or follow a consistent pattern across muscles. Therefore, maximum $T_{1}$ recovery rather than control $T_{\text {, }}$ was used to calculate the recovery time.

\section{SUCCINYLCHOLINE}

Time to maximum $T_{\text {, }}$ depression after the initial dose of succinylcholine, $100 \mu \mathrm{g} \cdot \mathrm{kg}^{-1}$, was shorter at the diaphragm $[52 \pm 9 \mathrm{sec}(\mathrm{SE})]$ and laryngeal muscles (61 $\pm 4 \mathrm{sec})$ than at the abdominal $(-90 \mathrm{sec})$ and limb muscles (>90 sec). Exact onset times could not be measured in the limb and abdominal muscles because in three goats the second dose was given as recovery started in

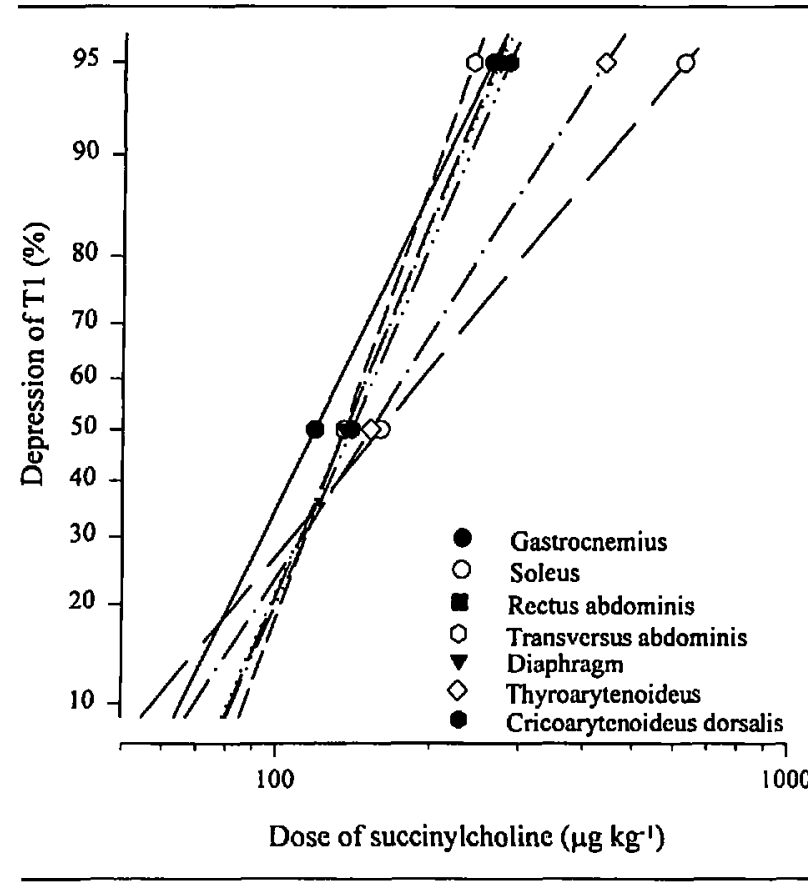

FIGURE 1 Dose-response curves for succinylcholine at the gastrocnemius, soleus, transversus abdominis, rectus abdominis, diaphragm, thyroarytenoideus and cricoarylenoideus dorsalis muscles obtained by the cumulative-dose response technique. The logit transformation of $T_{1}$ depression is plotted against the logarithm of the cumulative dose and the lines obtained by linear regression. Error bars are omilted for clarity.

the diaphragm and laryngeal muscles, before maximum depression of $T_{1}$ was reached in the limb and abdominal muscles.

The cumulative dose-response curves and pharmacodynamic data for succinylcholine are presented in Figure 1 and Table $\mathrm{I}$. The $\mathrm{ED}_{50} \mathrm{~s}$ did not differ among muscles $(P=0.6955)$. Maximum blockade after a cumulative dose of succinylcholine, $200 \mu \mathrm{g} \cdot \mathrm{kg}^{-1}$, was also not different among muscles ( $P=0.3985$; Table I).

In each goat, recovery of evoked response occurred in the order laryngeal muscles, diaphragm and limb muscles and then abdominal muscles and there were differences among muscles $(P=0.0001)$. The duration for spontaneous recovery of evoked response to $25 \%$ or $50 \%$ of maximal $\mathrm{T}_{1}$ recovery was shorter at the laryngeal muscles than at the abdominal muscles $(P<0.05$; Table I).

\section{VECURONIUM}

Onset of maximum $T_{1}$ depression after vecuronium, 2 $\mu \mathrm{g} \cdot \mathrm{kg}^{-1}$, was faster at the diaphragm $(3.9 \pm 0.5 \mathrm{~min})$ and laryngeal muscles $(4.3 \pm 0.5 \mathrm{~min})$ than at abdominal $(\sim 5.0 \mathrm{~min})$ and limb (>>5 min) muscles. In two goats recovery of evoked response started in the diaphragm and laryngeal muscles before maximum depression of 
TABLE I The mean ( $\pm \mathrm{SE}$ ) $\mathrm{ED}_{50}$, maximum blockade after succinylcholine, $200 \mu \mathrm{g} \cdot \mathrm{kg}^{-1}$, and duration for spontaneous recovery of $T_{1}$ to $25 \%$ and $50 \%$ of maximum evoked EMG recovery.

\begin{tabular}{lllcl}
\hline Muscle & $\begin{array}{l}E D_{50} \\
\left(\mu \mathrm{g} \cdot \mathrm{kg}^{-1}\right)\end{array}$ & $\begin{array}{l}\text { \% blockade after } \\
200 \mu \mathrm{g} \cdot \mathrm{kg}^{-1}\end{array}$ & $\begin{array}{l}\text { Minutes to } \\
25 \% T_{t}\end{array}$ & $\begin{array}{l}\text { Minutes to } \\
50 \% \mathrm{~T}_{l}\end{array}$ \\
\hline 1 Thyroarylenoideus & $152 \pm 20$ & $78 \pm 5$ & $5.2 \pm 1.5^{*}$ & $10.0 \pm 1.6^{*}$ \\
2 Cricoarytenoideus dorsalis & $140 \pm 26$ & $78 \pm 8$ & $6.3 \pm 2.0^{*}$ & $11.7 \pm 2.4^{*}$ \\
3 Soleus & $159 \pm 20$ & $68 \pm 9$ & $15.9 \pm 6.5$ & $22.1 \pm 8.4$ \\
4 Diaphragm & $136 \pm 10$ & $88 \pm 2$ & $17.3 \pm 4.4$ & $29.8 \pm 2.1$ \\
5 Gastrocnemius & $119 \pm 11$ & $85 \pm 4$ & $19.6 \pm 5.4$ & $30.3 \pm 2.7$ \\
6 Transversus abdominis & $135 \pm 9$ & $87 \pm 9$ & $31.1 \pm 3.7$ & $44.8 \pm 5.3$ \\
7 Recuus abdominis & $136 \pm 11$ & $86 \pm 8$ & $31.6 \pm 3.9$ & $45.1 \pm 4.5$ \\
\hline
\end{tabular}

* $P<0.05$ compared with the abdominal muscles.

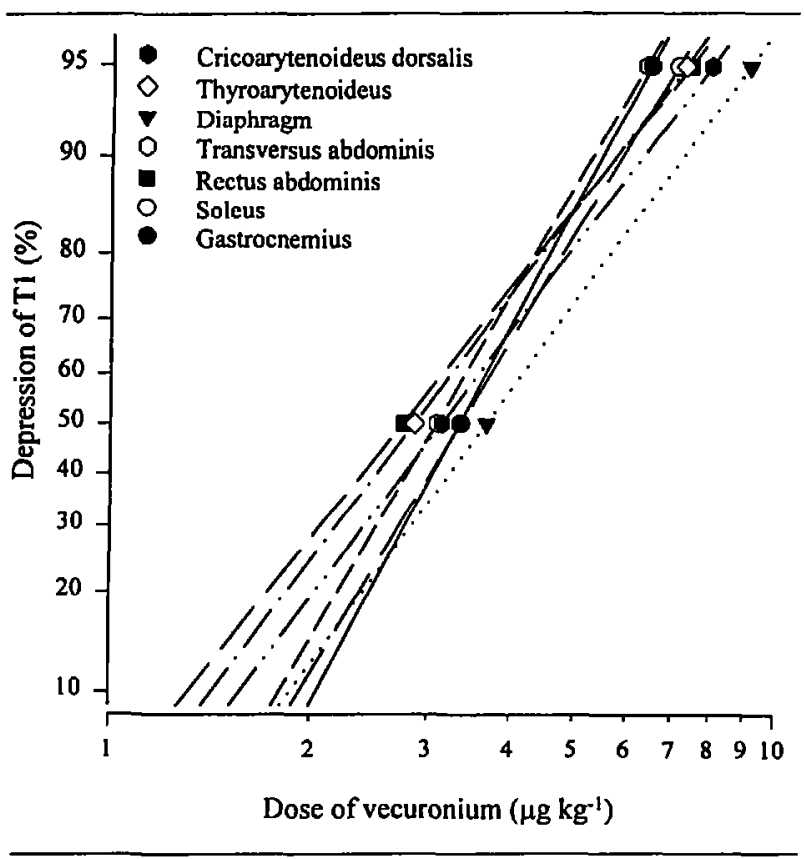

FIGURE 2 Dose-response curves for vecuronium at the gastrocnemius, soleus, rectus abdominis, transversus abdominis, diaphragm, cricoarytenoideus dorsalis and thyroarytenoideus muscles obtained by the cumulative-dose response method. The logit transformation of $T_{1}$ depression is plotted against the logarithm of the cumulative dose and the lines obtained by linear regression. Error bars are omitted for clarity.

$T_{1}$ was reached in the limb and abdominal muscles so that incremental doses had to be given apparently before maximum blockade was achieved in all muscles.

The cumulative dose-response curves and pharmacodynamic responses of the seven muscles to vecuronium are presented in Figure 2 and Table II. There were no differences among muscles in the $\mathrm{ED}_{50} \mathrm{~s}(P=0.7884)$ or maximum $T_{1}$ depression after a cumulative dose of vecuronium, $4 \mu \mathrm{g} \cdot \mathrm{kg}^{-1}(P=0.9528)$. There were differences in the duration for spontaneous $\mathrm{T}$, recovery to $25 \%$ or $50 \%$ of maximum response $(P=0.0001)$. Duration to $25 \% \mathrm{~T}_{1}$ increased in the same order as for succinylcholine (laryngeal, diaphragm and limb, and then abdominal muscles) and was longer at the abdominal muscles than at the cricoarytenoideus dorsalis muscle as well as longer at the transversus abdominis than at the diaphragm $(P<0.05)$. Duration to $50 \% \mathrm{~T}_{1}$ was longer at the abdominal muscles than at the other muscles $(P<0.05$; Table II $)$.

Comparison between succinylcholine and vecuronium There was a positive correlation between the rank order of duration to $25 \%$ ( $\mathrm{r}=0.714 ; P<0.05$ ) or $50 \%$ ( $\mathrm{r}=$ $0.865 ; P<0.05) \mathrm{T}$, recovery after succinylcholine and vecuronium (Spearman's rank correlation). That is, muscles that recovered early from succinylcholine also recovered early from vecuronium and vice versa. The rank order of the $\mathrm{ED}_{50} \mathrm{~s}$ or maximum blockade after a cumulative dose of succinylcholine, $200 \mu \mathrm{g} \cdot \mathrm{kg}^{-1}$, did not correlate with that after vecuronium. That is, that succinylcholine produced a greater degree of blockade in muscle ' $A$ ' than in muscle ' $B$ ' did not imply that vecuronium will affect muscle ' $A$ ' more than muscle 'B'.

\section{Correlation between structural characteristics and muscle response}

\section{SUCCINYLCHOLINE}

The duration until spontaneous $\mathrm{T}_{1}$ recovery of $25 \%$ or $50 \%$ correlated directly with mean fibre cross-sectional area ( $r \geq 0.56 ; P=0.0001$ ), and inversely with the ratio of endplate area to fibre cross-sectional area (i.e., the ESA:CSA ratio) ( $\geq 0.60 ; P=0.0001$ ) (Figure 3 ) or endplate surface area $(\mathrm{r}=0.40 ; P=0.015)$. Duration did not correlate with type I fibre composition ( $\mathrm{r} \leq 0.03 ; P \geq$ 0.83 ), acetylcholine receptor number ( $\mathrm{r} \leq 0.19 ; P \geq$ 0.26 ) or receptor density ( $\leq 0.16 ; P \geq 0.42$ ).

The $\mathrm{ED}_{50}$ correlated inversely with endplate surface area $(\mathrm{r}=0.53 ; P=0.0014)$ and directly with the ESA:CSA ratio $(r=0.47 ; P=0.0051)$, but did not correlate with fibre composition $(r=0.16 ; P=0.31)$, fibre 
TABLE II The mean ( $\pm \mathrm{SE}$ ) $\mathrm{ED}_{50}$, maximum blockade after vecuronium, $4 \mu \mathrm{g} \cdot \mathrm{kg}^{-1}$, and duration for spontaneous recovery of $T_{1}$ to $25 \%$ and $50 \%$ of maximum evoked EMG recovery.

\begin{tabular}{lllll}
\hline Muscle & $\begin{array}{l}E D_{50} \\
\left(\mu g \cdot \mathrm{kg}^{-1}\right)\end{array}$ & $\begin{array}{l}\text { \% blockade } \\
\text { after } 4 \mu \mathrm{g} \cdot \mathrm{kg}^{-1}\end{array}$ & $\begin{array}{l}\text { Minutes to } \\
25 \% T_{I}\end{array}$ & $\begin{array}{l}\text { Minutes to } \\
50 \% T_{I}\end{array}$ \\
\hline I Cricoarytenoideus dorsalis & $3.2 \pm 0.4$ & $81 \pm 3$ & $27.4 \pm 4.6$ & $41.5 \pm 5.9$ \\
2 Thyroarytenoideus & $2.9 \pm 0.3$ & $85 \pm 2$ & $34.7 \pm 4.2$ & $46.0 \pm 5.4$ \\
3 Diaphragm & $3.7 \pm 0.8$ & $77 \pm 7$ & $34.0 \pm 3.9$ & $55.0 \pm 2.8$ \\
4 Gastrocncmius & $3.4 \pm 0.4$ & $83 \pm 6$ & $38.8 \pm 3.7$ & $46.6 \pm 3.6$ \\
5 Soleus & $3.4 \pm 0.3$ & $80 \pm 5$ & $39.4 \pm 3.0$ & $46.6 \pm 2.2$ \\
6 Rectus abdominis & $2.8 \pm 0.2$ & $80 \pm 4$ & $57.7 \pm 9.2 *$ & $80.9 \pm 8.5 \ddagger$ \\
7 Transversus abdominis & $3.1 \pm 0.2$ & $81 \pm 5$ & $62.4 \pm 5.9 \dagger$ & $83.3 \pm 5.8 \S$ \\
\hline
\end{tabular}

$* P<0.05$ compared with cricoarytenoideus dorsalis.

$\dagger P<0.05$ compared with the diaphragm or cricoarytenoideus dorsalis.

$\ddagger P<0.05$ compared with laryngeal or limb muscles.

$\$ P<0.05$ compared with laryngeal. diaphragm or limb muscles.

cross-sectional area $(r=0.12 ; P=0.48)$, acetylcholine receptor number $(\mathrm{r}=0.013 ; P=0.94)$ or receptor density $(\mathrm{r}=0.12 ; P=0.55)$. Maximum $\mathrm{T}_{1}$ blockade after a cumulative dose of succinylcholine, $200 \mu \mathrm{g} \cdot \mathrm{kg}^{-1}$, did not correlate with any of these fibre morphological parameters.

\section{VECURONIUM}

After vecuronium, the duration to $25 \%$ or $50 \% \mathrm{~T}_{1}$ recovery correlated directly with mean fibre cross-sectional area ( $r \geq 0.40 ; P \leq 0.004$ ) and inversely with the ESA:CSA ratio ( $r \geq 0.40 ; P \leq 0.008$ ), but did not correlate with fibre composition, endplate surface area, acetylcholine receptor number or receptor density (Figure 4). The $\mathrm{ED}_{50} \mathrm{~s}$ or maximum $\mathrm{T}_{1}$ blockade after a cumulative dose of vecuronium, $2 \mu \mathrm{g} \cdot \mathrm{kg}^{-1}$, did not correlate with any of the fibre morphological parameters investigated.

\section{Discussion}

The above results indicate that in the goat (1) there are differences in the duration of action, but not the cumulative dose-response curves, of succinylcholine or vecuronium between the cricoarytenoideus dorsalis, thyroarytenoideus, diaphragm, rectus abdominis, transversus abdominis, gastrocnemius and soleus muscles; (2) there is not a reciprocal relationship in the relative durations of action between depolarizing versus non-depolarizing relaxants, hence if recovery is prolonged in one muscle with one type of drug, it is also prolonged with the other drug; (3) the relative responses of muscles to these relaxant drugs is not related to fibre type composition, junctional acetylcholine receptor numbers or receptor density per se; instead (4) the relative duration of action of either type of drug in muscles is related to mean muscle fibre diameter and the fraction of fibre circumference occupied by the motor endplate.

In order to investigate the influence of muscle mor- phology on sensitivity to relaxant drugs, first, it is necessary to study muscles that differ in both of these variables. This guided the choice of goats for this study since data are available on the morphology ${ }^{21-23}$ and, to a much lesser extent, the sensitivity to relaxant drugs ${ }^{14,19}$ of different muscles in this species. Secondly, it is important to assess sensitivity accurately. The ideal index of .muscle sensitivity to relaxant drugs is the concentration of the drug at the neuromuscular junction required for a given degree of blockade. ${ }^{24}$ Regrettably, it is not possible to measure drug concentrations at the neuromuscular junction, even in vitro. Since, at equilibrium the concentration of the drug in the plasma and at the neuromuscular junction may be considered equal, the degree of blockade produced by a given plasma drug concentration may be taken as a good index of the relative sensitivities of different muscles. However, such studies are technically difficult and expensive to perform because of the numerous determinations of plasma concentration involved and the requirement that steady-state be achieved. To date, only one study has measured plasma concentrations simultaneously with degree of blockade at two muscles. ${ }^{25}$ Since the concentration of the drug in plasma and the neuromuscular junction normally vary linearly with dose, most studies have used bolus or cumulative dose-response data to compare muscle sensitivity to relaxant drugs. ${ }^{\mid-7,11-13}$ However, dose-response curves may not reveal the 'true' relative sensitivities of muscles that differ in perfusion and onset time for maximum blockade especially for short-acting relaxants. Between the bolus and cumulative dose-response methods, the latter has the advantage of requiring fewer subjects to obtain a curve, but has the disadvantage of not being suitable for studying short-acting relaxants. Nevertheless, the cumulative dose-response method was used in this study because succinylcholine and vecuronium are much longer-acting 

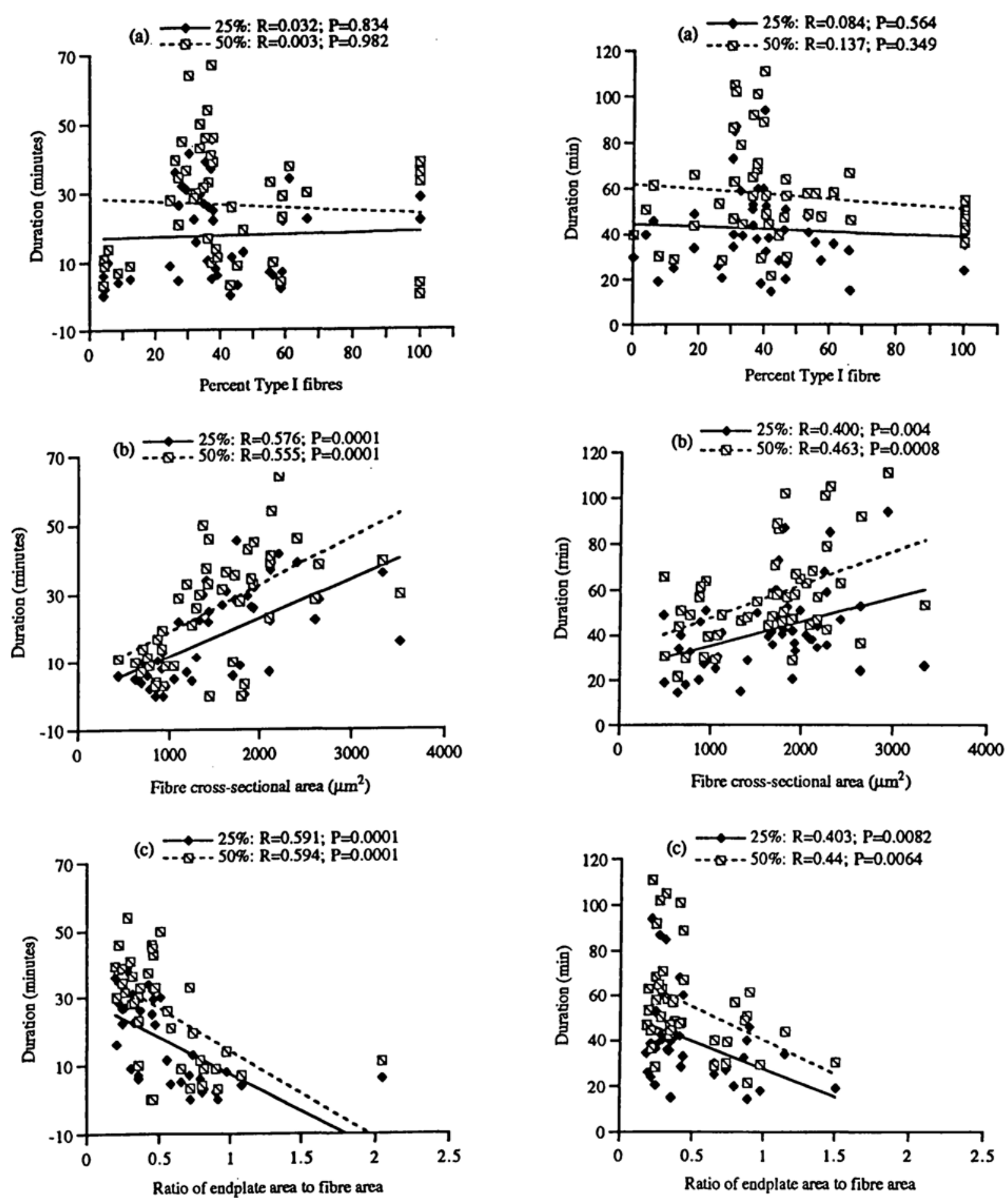

FIGURE 3 Regression analysis of the duration for spontancous recovery of $T_{1}$ to $25 \%$ or $50 \%$ of maximum recovery at the seven muscles after succinylcholine blockade versus (a) fibre type composition, (b) fibre cross-sectional area, and (c) the ratio of the endplate surface area to fibre cross-sectional arca. Notice the (a) lack of correlation between duration and fibre type composition, (b) direct correlation between duration and fibre cross-sectional area, and (c) inverse correlation between duration and the endplate to fibre size ratio.

FIGURE 4 Regression analysis of the duration for spontancous recovery of $T_{1} 1025 \%$ or $50 \%$ of maximum recovery at the seven muscles after vecuronium blockade versus (a) fibre type composition, (b) libre cross-sectional area, and (c) the ratio of the endplate surface area to fibre cross-sectional area. Notice the (a) lack of correlation between duration and fibre type composition, (b) direct correlation between duration and fibre cross-sectional area, and (c) inverse correlation belween duration and the endplate to fibre size ratio. 
drugs in the goat than in humans. In the present study, the duration to $25 \%$ recovery in limb muscles after a 1.0 $\times \mathrm{ED}_{95}$ dose was 15-20 min for succinylcholine and 39 min for vecuronium, much longer than the $-7 \min ^{26}$ and $20 \mathrm{~min}^{4}$ duration in humans after doses $\sim 1.75 \times \mathrm{ED}_{95}$ of succinylcholine and vecuronium, respectively. The long duration of action of succinylcholine in the goat may be explained by the low level of plasma cholinesterase activity in this species. ${ }^{27}$

The relatively long duration of action of vecuronium and succinylcholine in goats suggests that "pseudoequilibrium" (that is, between plasma and neuromuscular junction concentrations) was probably reached during recovery from blockade. Therefore, the duration of action may provide a better indication of the relative sensitivities of muscles to relaxant drugs than dose-response data which are affected by differences in blood flow during onset. Indeed, the present finding of differences in duration but not the $\mathrm{ED}_{50}$ among muscles suggests that these two indices might yield different indications of relative muscle sensitivity. Such discrepancies have been observed previously. For example, after vecuronium, $0.07 \mathrm{mg} \cdot \mathrm{kg}^{-1}$ given to humans, maximum blockade was found to be approximately the same at the diaphragm, the orbicularis oculi, and the adductor pollicis. However, onset and duration of action were markedly longer in the adductor pollicis. ${ }^{4}$ This discrepancy was interpreted as follows: a faster recovery indicates relative resistance of the diaphragm and the orbicularis oculi muscles, and the faster onset is due to their greater blood perfusion. However, this larger blood flow allows more muscle relaxant to be carried to the neuromuscular junction of these muscles immediately after injection. The net effect is that more drug reaches the diaphragm or the orbicularis oculi than the adductor pollicis but a similar degree of blockade is observed at all muscles because the first two are more resistant to the effect of the drug. ${ }^{4}$ A similar explanation would account for the greater intensity of succinylcholine blockade in human laryngeal adductor muscles than in the adductor pollicis muscle, although the onset time and duration of blockade were shorter in the laryngeal muscles. ${ }^{6}$

In humans, the diaphragm ${ }^{4,6}$ and laryngeal ${ }^{5.7}$ muscles are characterized by short onset times and duration of neuromuscular blockade compared with limb muscles. The same pattern was observed in the goat. ${ }^{19}$ However, the relationship between fast onset and resistance (or short duration) appears to be coincidental rather than causal. The onset time and duration of atracurium blockade are shorter in the rectus abdominis than in the adductor pollicis muscle of humans, ${ }^{28}$ but in the goat the onset of succinylcholine or vecuronium blockade is faster and yet the duration of action is longer in abdomi- nal muscles than in limb muscles. Also, the duration of action tends to be longer at the diaphragm than at laryngeal muscles in goats, in spite of a faster onset at the diaphragm.

Contrary to suggestions from previous studies which involved only three muscles, ${ }^{1.2}$ the relative sensitivity (duration of blockade) of muscles was similar for depolarizing and non-depolarizing relaxants, although these drugs produce their effects by different mechanisms. Secondly, sensitivity was not related to muscle fibre composition. Rather, the key factor in sensitivity common to both types of muscle relaxants appeared to be fibre size and the ratio of endplate size to fibre size. Muscles composed of large fibres tended to have a small endplate relative to fibre diameter and a greater sensitivity to muscle relaxants. The reasons for the association between duration of blockade and fibre size or the endplate to fibre size ratio are not clear. The following mechanism, based on the relationship between the electrical properties of muscle fibres and fibre diameter, is speculated for a non-depolarizing drug like vecuronium: Neuromuscular transmission occurs when the endplate potential reaches a certain threshold. The endplate potential is directly related to the endplate current, the duration of the endplate current, and the capacitance of the muscle fibre. The endplate current is determined by the number of receptor channels that are open, and the mean time they remain open is fixed. Thus, it is expected that at any level of paralysis, or receptor occupancy, the product of current and open time, or charge delivered to the endplate, remains constant. However, capacitance is proportional to muscle fibre diameter. For any charge delivered, voltage, which equals charge divided by capacitance is expected to be less and farther from action potential threshold if capacitance, or fibre diameter, is large. ${ }^{29}$ Hence large fibres tend to be more sensitive to muscle relaxants. This relationship between sensitivity and fibre size would not exist if large fibres had correspondingly large endplates, but this is not the case. ${ }^{20}$

It is more difficult to explain the relationship between duration of blockade and fibre size or the endplate to fibre size ratio for succinylcholine because there are uncertainties regarding its mechanism of action. The leading hypotheses include (1) desensitization of the endplate; (2) persistent depolarization of the endplate; and/or (3) inactivation of the sodium channels in the perijunctional area. ${ }^{30}$ Regarding the first possibility, one would expect that the same number of receptors would be bound to succinylcholine in all muscles, because receptor density and endplate size are comparable. ${ }^{20}$ If desensitization depends on the concentration of agonist, then this phenomenon would be the same in all muscles. 
If it depends on depolarization, one would expect a preferential effect on small fibres. On the other hand, the perijunctional zone is expected to be relatively more important if the endplate is small compared with fibre size. Thus, if inactivation of sodium channels was the main mechanism of action of depolarizing relaxants, a preferential effect on large fibres would be expected. This is in agreement with our findings.

Irrespective of the underlying mechanism, the association between duration of blockade and fibre size or the endplate to fibre size ratio was relatively weak suggesting that other factors contribute to determine muscle sensitivity to neuromuscular relaxants. Since relaxant drugs produce paralysis by preventing acetylcholine from interacting with postsynaptic acetylcholine receptors, it is conceivable that differences in prejunctional activity (for example, the number and size of quanta of acetylcholine released with each impulse) and acetylcholinesterase activity between muscles may contribute to the unequal sensitivities of muscles. It is not clear whether or how these variables differ among muscles or are related to fibre or endplate size.

In conclusion, the present results indicate that in the goat (1) the relative responses of muscles are the same for both depolarizing (succinylcholine) and non-depolarizing (vecuronium) relaxants; (2) dose-response data and duration of blockade might yield different indications of the relative sensitivities of muscles to relaxant drugs; and (3) the relative responses of muscles can be partly accounted for by differences in fibre size and the endplate size to fibre size ratio among muscles. However, it would appear that other factors and, possibly, interactions between them contribute to determine muscle sensitivity. Hence it may be too simplistic to assume that muscle sensitivity to relaxants is dependent on any single factor. Nevertheless, if similar relationships between muscle sensitivity and morphology can be shown to exist in other animal species and especially in humans, then knowledge of muscle fibre and neuromuscular junction morphology would help in predicting the sensitivity of any muscle to neuromuscular relaxants.

\section{Acknowledgement}

We wish to thank Mr. Eduardo Agurto for assistance with construction of the switch-box and maintenance of equipment used in this study.

\footnotetext{
References

1 Paton WDM, Zaimis EJ. The action of d-tubocurarine and decamethonium on respiratory and other muscles in the cat. J Physiol (Lond) 1951; 112: 311-31.

2 Alderson AM, Maclagan J. The action of decamethonium
}

and tubocurarine on the respiratory and limb muscles of the cat. J Physiol (Lond) 1964; 173: 38-56.

3 Kharkevich DA, Fisenko VP. The effect of neuromuscular blocking agents on the acetylcholine receptors of different skeletal muscles. Arch Int Pharmacodyn Ther 1981; 251: 255-69.

4 Donati F, Meistelman C, Plaud B. Vecuronium neuromuscular blockade at the diaphragm, the orbicularis oculi, and adductor pollicis muscles. Anesthesiology 1990; 73 : 870-5.

5 Donati F, Meistelman C, Plaud B. Vecuronium neuromuscular blockade at the adductor muscles of the larynx and adductor pollicis. Anesthesiology 1991; 74: 833-7.

6 Smith CE, Donati F, Bevan DR. Potency of succinylcholine at the diaphragm and at the adductor pollicis muscle. Anesth Analg 1988; 67: 625-30.

7 Meistelman C, Plaud B, Donati F. Neuromuscular effects of succinylcholine on the vocal cords and adductor pollicis muscles. Anesth Analg 1991; 73: 278-82.

8 Pavlin EG, Holle RH, Schoene RB. Recovery of airway protection compared with ventilation in humans after paralysis with curare. Anesthesiology 1989; 70: 381-5.

9 Isono S, Kochi T, Ide T, Sugimori K, Mizuguchi T, Nishino $T$. Differential effects of vecuronium on diaphragm and geniohyoid muscle in anaesthetized dogs. $\mathrm{Br} \mathrm{J}$ Anacsth 1992; 68: 239-43.

10 Day NS, Blake GJ, Standaert FG, Dretchen KL. Characterization of the train-of-four response in fast and slow muscles: effect of d-tubocurarine, pancuronium, and vecuronium. Anesthesiology 1983; 58: 414-7.

11 Choi $W W$, Gergis $S D$, Sokoll MD. Effects of succinylcholine chloride on the response of fast and slow muscle in the cat. Acta Anaesthesiol Scand 1984; 28: 516-20.

12 Secher NH, Rube N, Secher $O$. Effect of tubocurarine on human soleus and gastrocnemius muscles. Acta Anaesthesiol Scand 1982; 26: 231-4.

13 Choi $W W$, Gergis SD, Sokoll MD. The effects of d-tubocurarine, pancuronium and atracurium on the responses of gastrocnemius and soleus muscles in the cat. Acta Anaesthesiol Scand 1984; 28: 608-11.

14 Ibebunjo $C$, Hall LW. Suxamethonium and vecuronium neuromuscular blockade in two limb muscles of the goat. Journal of Veterinary Anaesthesia 1992; 19: 78-84.

15 lbebunjo $C$, Hall $L W$. Muscle fibre diameter and sensitivity to neuromuscular blocking drugs. $\mathrm{Br}$ J Anaesth 1993; 71: 732-3.

16 Maclagan J, Vrbova G. The importance of peripheral changes in determining the sensitivity of striated muscles to depolarizing drugs. J Physiol (Lond) 1966; 184 : 618-30.

17 Churchill-Davidson HC, Richardson AT. Decamethonium iodide (C10): some observation on its action using electromyography. Proc R Soc Med 1952; 45: 179-86. 
18 Waud $D B$, Waud DR. The margin of safety of neuromuscular transmission in the muscle of the diaphragm. Anesthesiology 1972; 37: 417-22.

19 Ibebunjo $C_{1}$ Hall $L W$. Succinylcholine and vecuronium blockade of the diaphragm, laryngeal and limb muscles in the anaesthetized goat. Can J Anaesth 1994; 41: 36-42.

20 Ibebunjo $C$, Srikant CB, Donati $F$. Properties of fibres, endplates and acetylcholine receptors in the diaphragm, masseter, laryngeal, abdominal and limb muscles in the goat. Can J Anaesth 1996; 43: 475-84.

21 lbebunjo $C$. Type, diameter and distribution of fibres in some respiratory and abdominal muscles of the goat. Vet Res Commun 1993; 17: 171-82.

22 lbebunjo $C$. Histochemical and morphometric properties of muscles of the upper airway of goats. Res Vet Sci 1993; 55: 215-23.

23 Ibebunjo $C$. Morphologic and morphometric characteristics of limb muscles of the goat. Small Ruminant Research 1994; 13: 277-86.

24 Stanski $D R$, Sheiner $L B$. Pharmacokinetics and dynamics of muscle relaxants. Anesthesiology 1979; 51: 103-5.

25 Plaud B, Proost JH, Wierda JMKH, Barré J, Debaene B, Meistelman $C$. Pharmacokinetics and pharmacodynamics of rocuronium at the vocal cords and the adductor pollicis in humans. Clin Pharmacol Ther 1995; 58: 185-91.

$26 K a t z R L$, Ryan $J F$. The neuromuscular effects of suxamethonium in man. Br J Anaesth 1969; 41: 381-90.

27 Faye $S A$. Investigations on plasma cholinesterase in man and animals using succinylcholine as the substrate. $\mathrm{PhD}$ Thesis, University of Leeds, UK, 1988.

28 Saddler JM, Marks LF, Norman J. Comparison of atracurium-induced neuromuscular block in rectus abdominis and hand muscles of man. Br J Anaesth 1992; 69: 26-8.

29 Katz $B$, Thesleff $S$. On the factors which determine the amplitude of the 'miniature end plate potential'. J Physiol (Lond) 1957; 137: 267-78.

30 Standaert FG. Neuromuscular physiology, In: Miller RD (Ed.). Anesthesia, 3rd ed. New York: Churchill Livingstone Inc., 1990: 659-84. 